\title{
Presentations to emergency departments for chronic obstructive pulmonary disease in Alberta: a population-based study
}

\author{
Rhonda J. Rosychuk, PhD, PStat; ${ }^{* \dagger}$ Donald C. Voaklander, PhD; ${ }^{\ddagger}$ Ambikaipakan Senthilselvan, PhD; \\ Terry P. Klassen, MD, MSc; ${ }^{* \dagger}$ Thomas J. Marrie, MD; ${ }^{\S}$ Brian H. Rowe, MD, MSc ${ }^{\ddagger \uparrow}$
}

\section{ABSTRACT}

Objective: Chronic obstructive pulmonary disease (COPD) is a widespread illness with an increasing prevalence in older adults; exacerbations resulting in visits to the emergency department (ED) are common. We sought to determine the epidemiology of COPD presentations to EDs by older adults in Alberta.

Methods: Administrative databases were used to examine all ED encounters for COPD from April 1999 to March 2005 in Alberta. Data included demographics of patients and timing of ED visits. Data analysis included descriptive summaries and age-sex directly standardized visit rates (DSVRs).

Results: There were 85330 ED visits for acute COPD made by 38638 patients 55 years of age or older during the study period. More men (53.2\%) presented, and the mean age at presentation was 72 years. The age-sex DSVRs remained stable from 2000/01 (24.4/1000) to 2004/05 (25.6/1000). Presentation rates differed among population subgroups. Overall, $67 \%$ of visits resulted in discharge from the ED.

Conclusion: Chronic obstructive pulmonary disease is a common presentation in Alberta EDs; however, the rates of presentation were stable during the study period, and monthly and hourly trends exhibited similar patterns for each year. Disparities based on age, sex, and socio-economic and cultural statuses were identified. Targeted interventions could be implemented to reduce future ED visits for COPD.

Keywords: chronic obstructive pulmonary disease, emergency medicine, epidemiology, respiratory diseases

\section{RÉSUMÉ}

Objectif : La maladie pulmonaire obstructive chronique (MPOC) est une maladie répandue dont la prévalence est plus grande chez les personnes âgées. Des exacerbations de MPOC sont couramment associées à des visites au service d'urgence. Nous avons cherché à déterminer l'épidémiologie de la MPOC chez des personnes âgées se présentant dans les urgences de l'Alberta.

Méthodes : Nous avons utilisé des bases de données administratives pour analyser toutes les visites à l'urgence de personnes atteintes de la MPOC d'avril 1999 à mars 2005 en Alberta. Les données recueillies comprenaient les données démographiques des patients ainsi que les dates des visites à l'urgence. L'analyse des données a donné lieu à des résumés descriptifs ainsi qu'à des taux de visite directement standardisés selon l'âge et le sexe.

Résultats: Au cours de la période de l'étude, 38638 patients de 55 ans ou plus ont fait 85330 visites à l'urgence pour la MPOC. De ce nombre, 53,2 \% étaient des hommes. L'âge moyen des patients était de 72 ans. Le taux de visite directement standardisé en fonction de l'âge et du sexe est demeuré stable de 2000-2001 $(24,4 / 1000)$ à $2004-2005(25,6 / 1000)$. Les taux de visite variaient selon les sous-groupes de population. Dans l'ensemble, le retour à domicile a été l'issue de $67 \%$ des visites.

Conclusion : La maladie pulmonaire obstructive chronique est un motif courant de visite à I'urgence en Alberta. Cependant, les taux de visite étaient stables au cours de la période de l'étude, et les tendances mensuelles et horaires affichaient des profils semblables chaque année de l'étude. Nous avons observé des disparités fondées sur l'âge, le sexe ainsi que le statut socio-économique et culturel. II conviendrait de mettre en place des interventions ciblées pour réduire les futures visites à l'urgence de personnes atteintes de la MPOC.

\footnotetext{
From the *Department of Pediatrics, University of Alberta, Edmonton, Alta., the tWomen and Children's Health Research Institute, Edmonton, Alta., the $¥$ School of Public Health, University of Alberta, Edmonton, Alta., the §Faculty of Medicine, Dalhousie University, Halifax, NS, and the IDepartment of Emergency Medicine, University of Alberta, Edmonton, Alta.
}

This study was presented at the Canadian Association of Emergency Physicians Annual Scientific Meeting, Calgary, Alta., Jun. 7, 2009.

Submitted Nov. 27, 2009; Revised Feb. 24, 2010; Accepted Apr. 23, 2010

This article has been peer reviewed.

CJEM 2010;12(6):500-8 


\section{INTRODUCTION}

Chronic obstructive pulmonary disease (COPD) is an illness of the lower respiratory tract. It varies in severity, and its intermittent exacerbations are characterized by ongoing symptoms of cough, sputum production and shortness of breath. ${ }^{1}$ The economic cost of COPD is staggering, ${ }^{2}$ and it was predicted that COPD would be the leading cause of death from chronic disease by 2010. ${ }^{3}$ Patients with COPD often experience exacerbations due to any or a combination of respiratory infections, nonadherence with medications and passive or active cigarette smoke exposure. Some exacerbations are severe enough to precipitate a visit to an acute care setting such as a physician's office, a walk-in clinic or the emergency department (ED); many patients require prolonged treatment in the ED. Hospital admission is a common outcome in severe exacerbations, and some exacerbations result in complications including pneumothorax, intubation and mechanical ventilation and, on occasion, death.

The vast majority of patients with COPD are older adults, in whom the disease is of gradual onset and varying severity that typically worsens over time. Smoking is the most common causative agent in this population, although occupational exposures, drug abuse, genetic susceptibility and rare primary and secondary lung diseases can also be contributory. Although a small proportion of COPD cases occur in younger age groups, these patients have chronic lung disease of childhood, $\alpha-1$ anti-trypsin deficiency and other disorders. With appropriate management including smoking cessation, and long-term and acute pharmacologic and nonpharmacologic interventions, patients can reduce deterioration, improve their quality of life and reduce the severity and frequency of exacerbations. As COPD is a chronic disease with frequent exacerbations, ED presentations for COPD are important health care events for patients and the health care system.

The purpose of this study was to describe the epidemiology of older adults (defined as age $\geq 55 \mathrm{yr}$ ) who presented to EDs for COPD during 6 fiscal years (Apr. 1, 1999, to Mar. 31, 2005). Using populationbased administrative health databases from the province of Alberta, we examined the trends in overall presentation rates over time, the presentation rates for different population subgroups, the timing of presentations and the outcomes at the conclusion of $\mathrm{ED}$ visits.
METHODS

\section{Study design}

We conducted a retrospective cross-sectional study using prospectively collected administrative data.

\section{Setting}

In Canada, health care is universal, accessible and portable from province to province. The management and delivery of health care is the responsibility of each province or territory. As in other provinces, all residents of Alberta can access free health care, assuming they are eligible for and maintain health insurance through the Alberta Health Care Insurance Plan. Self-employed residents pay their own health care premiums. For those without financial means to fully or partially pay for this insurance, subsidies exist.

\section{Data and variable description}

We accessed the Ambulatory Care Classification System (ACCS) ${ }^{4}$ of the province of Alberta. This is a system for tracking the use of ambulatory care services to government-funded facilities within the province. All ED encounters from more than 100 provincial EDs are entered into computerized abstracts that constitute the majority of records. Using a uniform protocol, trained and supervised medical records nosologists code each chart using ICD-9-CM ${ }^{5}$ (before Apr. 1, 2002) or ICD10-CA ${ }^{6}$ (Apr. 1, 2002 and onward) diagnostic codes.

Each ACCS record represents a unique service and includes a unique identifier for each Albertan, visit start and end dates and times, diagnoses and disposition information. Demographic data were obtained by linking patients in the ACCS to the annual Alberta Health Care Insurance Plan cumulative registry file. This file includes all people registered under the Alberta Health Care Insurance Plan at any time in a given year (approximately $99 \%$ of the provincial population). The demographic information available included age, sex and socio-economic proxy. The focus of this study was patients aged 55 years or older presenting to EDs from Apr. 1, 1999, to Mar. 31, 2005.

Diagnostic information in the ACCS consists of a main ambulatory diagnosis field, and 5 and 9 additional fields for ICD-9-CM and ICD-10-CA codes, respectively. To be considered a COPD-related visit, the first or second diagnosis fields in the ACCS were required to 
have diagnostic codes encompassing COPD, chronic airway obstruction, bronchitis, emphysema and bronchiectasis (490.x, 491.x, 492.x, 494, 496, J40.x, J41.x, J42.x, J43.x, J44.x, J47.x). Injury and medical studies using ACCS data indicate that the coded diagnosis is accurate in approximately $97 \%$ of cases. ${ }^{7-9}$

The ACCS includes the start and end dates and times for each ED visit. The difference between the end date and time and the start date and time provided the duration of service. All patients departing from an ED are given 1 of 9 disposition classifications according to the manner in which they are released from the ambulatory service facility. All patients are coded as either male or female. Only patients 55 years of age or older at the time of the ED visit were included in this study. Age was categorized into the following groups: 55-59, 60-64, 65-69, 70-74, 75-79, 80+ years. Until 2008, Alberta had 9 regional health authorities responsible for the delivery of health care services. ${ }^{10}$ Region of residence was based on location of residence at the end of the fiscal year. The 2 largest urban regional health authorities are the cities and surrounding areas of Edmonton and Calgary.

The Alberta government funds health care in the province, and health care insurance premiums provide partial funding. Residents with lower incomes or receiving social services are eligible for premium subsidies. The subsidy level can be used as a proxy measure for socio-economic status. The subsidy level variable combines data from various fields for patients younger than 65 years into 4 categories: "Aboriginal with treaty status," "Welfare," "Government sponsored programs" and "Registrant without subsidy." Aboriginal with treaty status includes all Aboriginal people in Alberta who have treaty status based on treaties between their First Nation band and the Canadian government. ${ }^{11}$ The Welfare category represents people who receive income support and health benefits from the province of Alberta because they do not have sufficient resources to meet basic needs. Albertans with lower incomes who receive partial or full subsidies for their health care insurance premiums or those receiving disability benefits comprise the Government sponsored programs group.

\section{Outcome measures}

The main outcomes for this study were descriptive; counts and proportions are reported with corresponding $95 \%$ confidence intervals (CIs). We specifically examined age-specific rates, directly standardized visit rates (DSVRs) and admission proportions.

\section{Data analysis}

Data on the ED visits between Apr. 1, 1999, and Mar. 31, 2005, were extracted. Frequencies and percentages summarize categorical data, and continuous data are summarized by median and interquartile range or mean and standard deviation (SD). Age-specific ED visits per 1000 older adult population (age $\geq 55 \mathrm{yr}$ ) were calculated for each sex. The DSVRs ${ }^{12}$ use the 1999/2000 Alberta older adult population as the reference population. Directly standardized visit rates are calculated, reported with $95 \%$ CIs and compared across groups. ${ }^{12}$ Summaries by subsidy level are restricted to patients younger than 65 years. To ensure patients were not identifiable, small counts $(\leq 5)$ were supressed. S-Plus ${ }^{13}$ was used for analysis, and $p<0.05$ was considered to be statistically significant. Whereas all years were included in the analysis, when patterns among years were similar, the results focused on the last year of data.

The study was approved by the University of Alberta Health Research Ethics Board.

\section{RESULTS}

\section{Study participants}

Data were extracted on 38638 patients with a mean age of 72.0 (SD 10.1) years. Just over half $(50.3 \%$ ) of the patients included in our analysis were female (19 221 men, 19417 women). Most lived in the areas outside the 2 major urban areas (26.7\% in Edmonton, 19.4\% in Calgary, 53.9\% elsewhere). There were 11362 patients between the ages of 55 and 64 years during any of the study years. Whereas subsidy group changed for some patients over a fiscal year, at the time of first presentation during our study period, $60.1 \%, 19.6 \%, 13.0 \%$ and $7.3 \%$ of study participants were classified in the Registrant without subsidy, Government sponsored program, Welfare and Aboriginal groups, respectively.

\section{General trends}

During the study period, the Alberta adult population aged 55 years and older increased (Table 1) and senior citizens (age $\geq 65 \mathrm{yr}$ ) represented just over half of this population. Of the Alberta population aged 55-64 years in $2004 / 05,1.9 \%, 76.1 \%, 17.9 \%$ and $4.2 \%$ were part of Aboriginal, Registrant without subsidy, Government sponsored program and Welfare groups, respectively. Visits to the ED for any reason by older adults in Alberta 
increased from 352817 in 1999/2000 to 424877 in 2004/05. The COPD-related ED visits also increased from 13602 visits in 1999/2000 to 16110 visits in $2004 / 05$, accounting for about $3.8 \%$ of the total visits in this age group per year.

Overall, $85330 \mathrm{ED}$ visits for COPD were made by 38638 patients, with an average of 2.2 visits per patient (median 1, interquartile range 1-2). The majority (24 633, 63.8\%) visited the ED only once, and 6208 (16.1\%), 2702 (7.0\%), $1452(3.8 \%), 906(2.3 \%)$ and $2737(7.1 \%)$ patients visited the ED 2, 3, 4, 5 and 6 or more times, respectively.

\section{Age and sex}

The majority of ED visits for COPD (75.3\%, 64292 visits) were made by seniors (age $\geq 65 \mathrm{yr}$, Table 2). Overall, visits by men exceeded visits by women (45 370 [53.2\%] v. 39960 [46.8\%]) despite the fact that there were slightly more female study participants $(50.3 \%)$; however, these differences were small. Whereas the visit rates in the age groups 55-59 and 60-64 were comparable for men and women, the higher age groups displayed more pronounced differences (Fig. 1). The visit rate for men in the 80 or older age group was nearly double the rate for women (66.0/1000 for men v. 33.1/1000 for women in 2004/05). A similar pattern was observed for the other fiscal years. After adjustment for age group and sex, the DSVRs remained relatively stable over time, ranging from $21.8 / 1000$ in $2002 / 03$ to $25.6 / 1000$ in $1999 / 2000$ and 2004/05.

Table 1. Emergency department visits for chronic obstructive pulmonary disease by adults aged 55 years or older in Alberta from Apr. 1, 1999, to Mar. 31, 2005

\begin{tabular}{lccccc}
\hline Fiscal year & $\begin{array}{c}\text { Total no. of ED visits } \\
\text { for all conditions }\end{array}$ & $\begin{array}{c}\text { No. of ED visits for COPD } \\
\text { (\% of total) }\end{array}$ & $\begin{array}{c}\text { No. of patients who } \\
\text { visited the ED for COPD }\end{array}$ & $\begin{array}{c}\text { Alberta older adult } \\
\text { population }\end{array}$ & $\begin{array}{c}\text { Crude visit rate per } 1 \text { 000 } \\
\text { older adult population }\end{array}$ \\
\hline 1999/2000 & 352817 & $13602(3.9)$ & 8750 & 531467 & 25.6 \\
$2000 / 01$ & 369038 & $13386(3.6)$ & 8323 & 548534 & 24.4 \\
$2001 / 02$ & 382183 & $14116(3.7)$ & 8749 & 572529 & 24.7 \\
$2002 / 03$ & 400503 & $12891(3.2)$ & 8448 & 597085 & 21.6 \\
$2003 / 04$ & 422798 & $15225(3.6)$ & 10485 & 618445 & 205 \\
$2004 / 05$ & 424877 & $16110(3.8)$ & & & \\
\hline
\end{tabular}

Table 2. Demographic characteristics of emergency department visits for chronic obstructive pulmonary disease in Alberta, by fiscal year

\begin{tabular}{|c|c|c|c|c|c|c|}
\hline \multirow[b]{2}{*}{ Characteristic } & \multicolumn{6}{|c|}{ Fiscal year; no. (\%) of patients } \\
\hline & $\begin{array}{l}1999 / 2000 \\
n=13602\end{array}$ & $\begin{array}{c}2000 / 01 \\
n=13386\end{array}$ & $\begin{array}{c}2001 / 02 \\
n=14116\end{array}$ & $\begin{array}{c}2002 / 03 \\
n=12891\end{array}$ & $\begin{array}{c}2003 / 04 \\
n=15225\end{array}$ & $\begin{array}{c}2004 / 05 \\
n=16110\end{array}$ \\
\hline \multicolumn{7}{|l|}{ Sex } \\
\hline Male & $7434(54.7)$ & $7125(53.2)$ & $7517(53.3)$ & $6864(53.2)$ & $7864(51.7)$ & $8566(53.2)$ \\
\hline Female & $6168(45.3)$ & $6261(46.8)$ & $6599(46.7)$ & $6027(46.8)$ & 7361 (48.3) & $7544(46.8)$ \\
\hline \multicolumn{7}{|l|}{ Age group, yr } \\
\hline $55-59$ & $1537(11.3)$ & $1574(11.8)$ & $1626(11.5)$ & $1370(10.6)$ & $1986(13.0)$ & $2010(12.5)$ \\
\hline $60-64$ & $1769(13.0)$ & 1709 (12.8) & $1832(13.0)$ & $1616(12.5)$ & $1975(13.0)$ & $2034(12.6)$ \\
\hline $65-69$ & $2152(15.8)$ & $2171(16.2)$ & $2317(16.4)$ & $2066(16.0)$ & $2418(15.9)$ & $2435(15.1)$ \\
\hline $70-74$ & $2541(18.7)$ & $2339(17.5)$ & $2648(18.8)$ & $2296(17.8)$ & $2638(17.3)$ & $2848(17.7)$ \\
\hline $75-79$ & $2660(19.6)$ & $2422(18.1)$ & $2458(17.4)$ & $2271(17.6)$ & $2583(17.0)$ & $2888(17.9)$ \\
\hline$\geq 80$ & $2943(21.6)$ & $3171(23.7)$ & 3235 (22.9) & $3272(25.4)$ & $3625(23.8)$ & $3895(24.2)$ \\
\hline \multicolumn{7}{|l|}{$\begin{array}{l}\text { Subsidy group, for patients aged } \\
55-64 \text { yr only }\end{array}$} \\
\hline Aboriginal & $221 \quad(6.7)$ & 262 (8.0) & 333 (9.6) & 257 (8.6) & 347 (8.8) & $311(7.7)$ \\
\hline Government sponsored programs & $804(24.3)$ & $745(22.7)$ & $646(18.7)$ & $535(17.9)$ & $648(16.4)$ & $975(24.1)$ \\
\hline Registrant without subsidy & $1823(55.1)$ & $1718(52.3)$ & $1852(53.6)$ & $1669(55.9)$ & $2211(55.8)$ & $2025(50.1)$ \\
\hline Welfare & $458(13.9)$ & $558(17.0)$ & $627(18.1)$ & $525(17.6)$ & $755(19.1)$ & $733(18.1)$ \\
\hline
\end{tabular}




\section{Special populations}

In 2004/05, the majority of ED visits for COPD (50.1\%, 2025/4044) by adults aged 55-64 years were made by the Registrants without subsidy group. The Aboriginal, Welfare and Government sponsored program groups represented $1.9 \%$ (5778 people), $4.2 \%$ (12 609 people) and $17.9 \%$ (54 111 people) of the 302989 population aged 55-64 years in 2004/05, respectively; however, with $7.7 \%$ (311/4044), 18.1\% (733/4044) and 24.1\% (975/4044) visits, respectively, these groups had disproportionately more ED visits. These patterns were similar for all years.

The sex- and age-specific ED visit rates varied considerably by subsidy group (Fig. 2). In 2004/05, the Welfare and Aboriginal groups had larger age group-

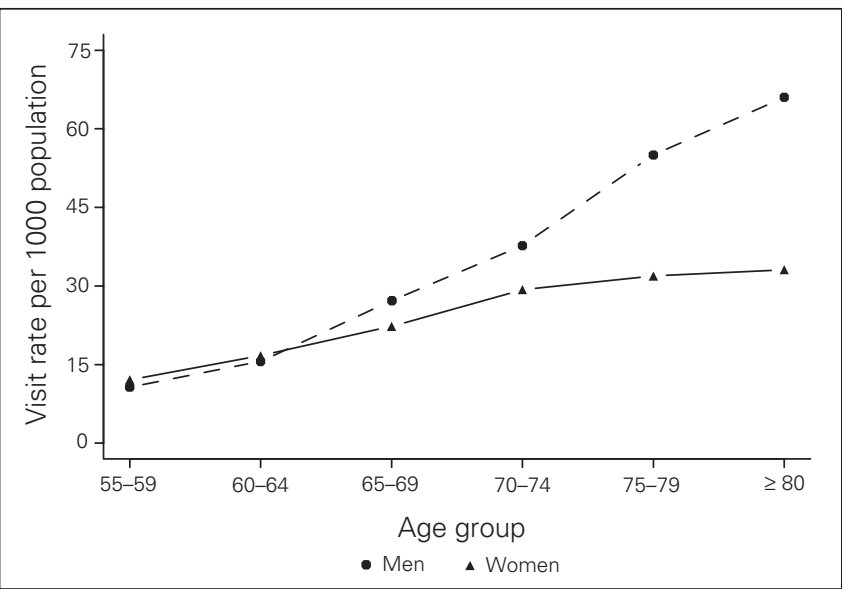

Fig. 1. Age-specific emergency department visit rates for chronic obstructive pulmonary disease per 1000 older adult population in 2004/05.

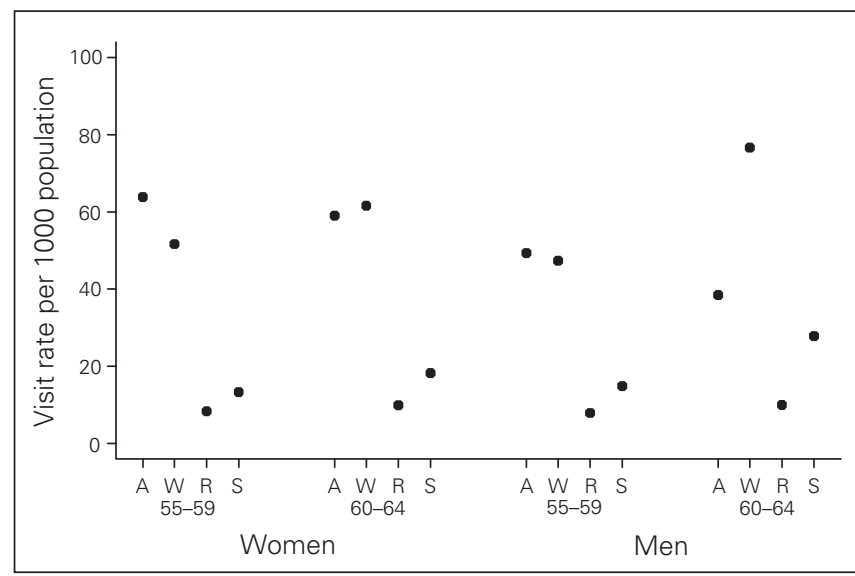

Fig. 2. Age-specific emergency department visit rates for chronic obstructive pulmonary disease per 1000 population (age 55-64 yr) in 2004/05 by sex and subsidy group: Aboriginal (A), Welfare (W), Registrant without subsidy (R) and Government sponsored programs (S). specific ED visits rates compared with the other groups, especially for women. The DSVRs differed significantly among the 4 subsidy groups (Fig. 3, $p<0.001$ in each year). The Registrant without subsidy and the Government sponsored groups displayed similar trends; however, the considerably higher Aboriginal and Welfare rates were more similar. In 2004/05, the Welfare (58.2/1000) and Aboriginal (53.1/1000) DSVRs were higher than the other 2 groups (Government sponsored 18.1/1000, Registrant without subsidy 8.9/1000; $p<$ $0.001)$.

\section{Visit timing}

In 2004/05, visits ranged from 1047 to 1867 per month and had higher peaks in January and March (Fig. 4). Mondays had slightly higher volumes than the other

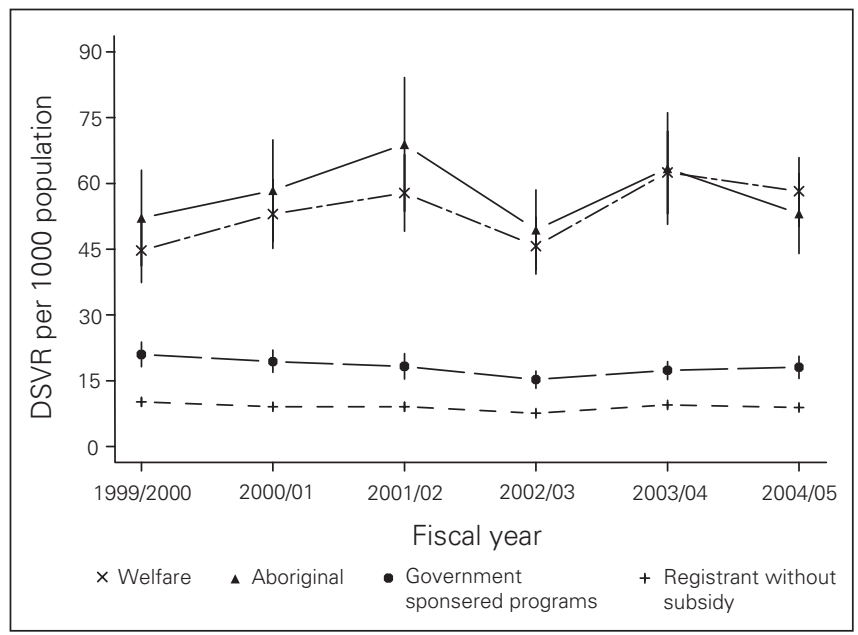

Fig. 3. Age group and sex directly standardized visit rates (DSVRs) per 1000 population (age < $65 \mathrm{yr}$ ) for each fiscal year (together with $95 \%$ confidence intervals) by subsidy group.

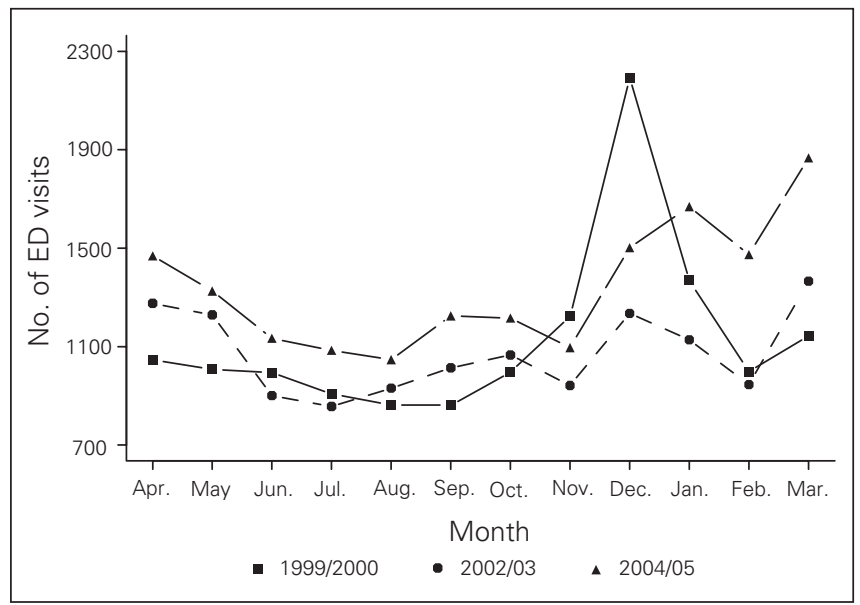

Fig. 4. Frequency of emergency department visits, by month. 
days of the week, with 2506 (15.6\%) visits. Other years had similar patterns. Visits for COPD were less frequent during the early morning hours (midnight to 7:00 am) and peaked during the early day time hours (8:00 am to $11: 00 \mathrm{am})$.

\section{Admissions}

The majority of visits for COPD concluded in discharge from the $\mathrm{ED}(67.2 \%, 57375)$, and the proportion of patients discharged was similar from year to year (Table 3). Admissions were reported for 32.5\% (27 705) of the ED visits. A small proportion of admissions were to the critical care unit or operating room, and the vast majority were to other areas. Relatively few deaths occurred.

\section{Regional variation}

Emergency department visits for COPD in Calgary, Edmonton and all other regions numbered 15500 (18.2\%), 21706 (25.4\%) and 48121 (56.4\%), respectively. Most patients visited EDs in the same region as their residence $(94.4 \%, 80$ 560). The DSVRs remained relatively stable over time for each region (Table 4). Calgary and Edmonton had lower rates than most of the other regions and were below the Alberta average (Fig. 5).

The pronounced peak of visits between 8:00 am and 11:00 am (Fig. 4) was mainly based on the nonmajor urbanized areas: Calgary and Edmonton had gradual increases from 8:00 am to 10:00 am that subsequently declined steadily.

\section{DISCUSSION}

This study explored visits for acute COPD to more than 100 Alberta EDs during a 6-year period. By using a large provincial database with linkage capabilities to a demographic data registry, we were able to obtain comprehensive information on all visits for COPD made to EDs in this province. The results from this study identify important epidemiologic trends and outcome information that have not been previously reported.

First, the overall number of ED visits for COPD has generally increased; however, the rate of visits has remained the same. These results are similar to US data from the National Hospital Ambulatory Medical Care Survey, which failed to identify a statistically significant trend in ED visits for COPD over an 8-year study period (1993-2005). ${ }^{14}$ A variety of potential explanations exist for our failure to identify increased rates, despite worldwide statistics that suggest increasing prevalence of the disease..$^{15}$ For example, ED overcrowding has been a growing concern across North America, especially in high-volume, urban and teaching centres, and patients with COPD occupy ED stretchers for prolonged periods. ${ }^{16}$ Like many patients, COPD patients may select alternative after-hours treatment whenever possible. Access to all care is free to Canadians with government-sponsored health insurance, and access to

Table 3. Emergency department visits for chronic obstructive pulmonary disease by patients aged 55 years or older, by disposition category and fiscal year

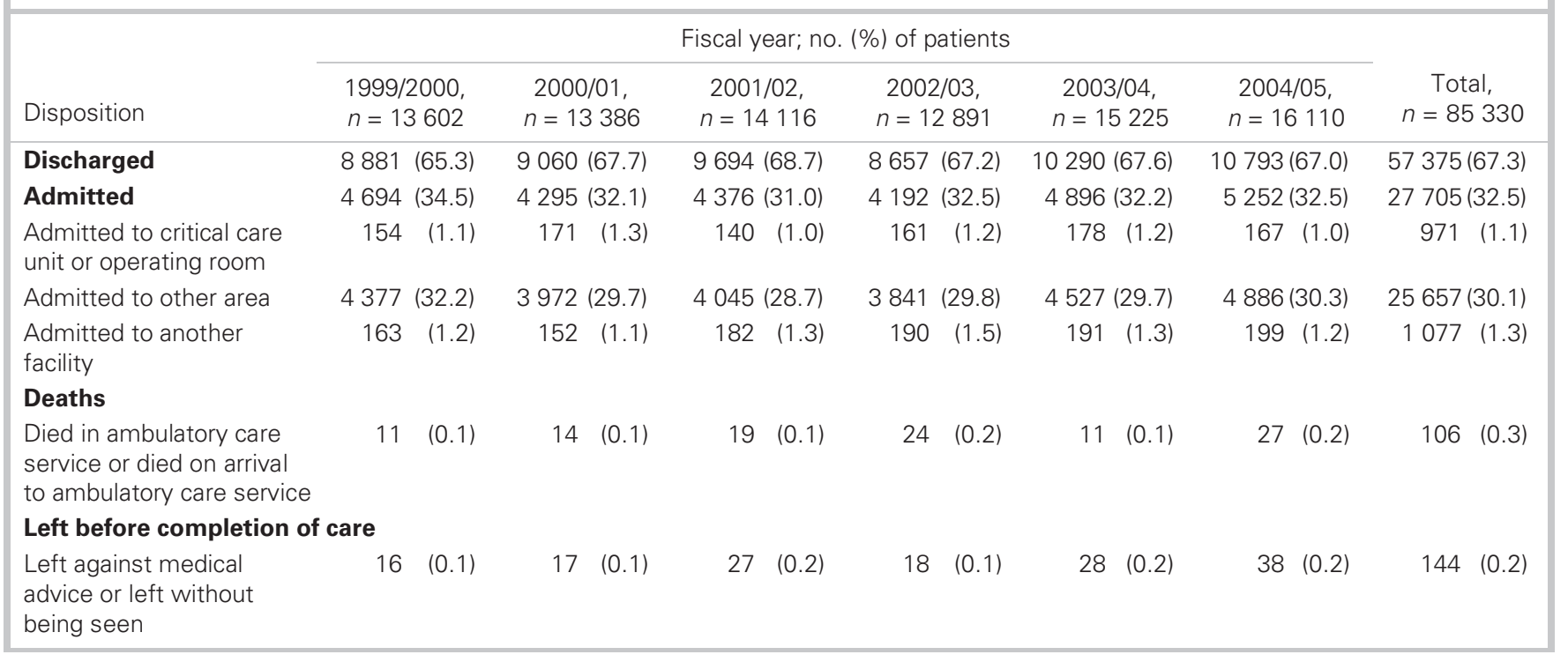


after-hours care has improved with the development of walk-in clinics and urgent care centres in most urban and semiurban centres. The use of inhaled long-acting anticholinergic agents, long-acting $\beta 2$-agonists and corticosteroid agents, alone or in combination, to prevent deterioration has likely further improved control of COPD and reduced ED visits for exacerbation. ${ }^{17}$

Second, our results provide additional data regarding some important "high-risk" populations. We found that rates of ED visits were particularly high among people aged 55-64 years with Aboriginal status or receiving welfare. In general, physician claims data have shown that Aboriginal Albertans have higher rates of respiratory illness. ${ }^{18}$ Whereas men over the age of 65 are more likely to visit an ED for COPD than women, these data do not necessarily mean that women are at lower risk for COPD. Considerable data exist to suggest that women have an increasing incidence of COPD. ${ }^{19}$ Moreover, other ED research suggests that men and women who present to the ED for treatment of COPD exacerbations have substantial differences in chronic medication use, self-treatment during exacerbations, delay in emergency care and post-ED outcomes. ${ }^{20}$ It is likely that rates and severity of COPD presentations for women will increase in the future, and treatments will need to be targeted to these patients. Because $36 \%$ of our sample had a repeat ED visit for COPD during the study period, it is possible that targeted interventions could be implemented to reduce repeat ED visits and improve outcomes.

Third, using standardized visit rates, we identified regional variations. In 2004/05, rates were lowest in the 2 largest and most urban areas of the province. Differ-

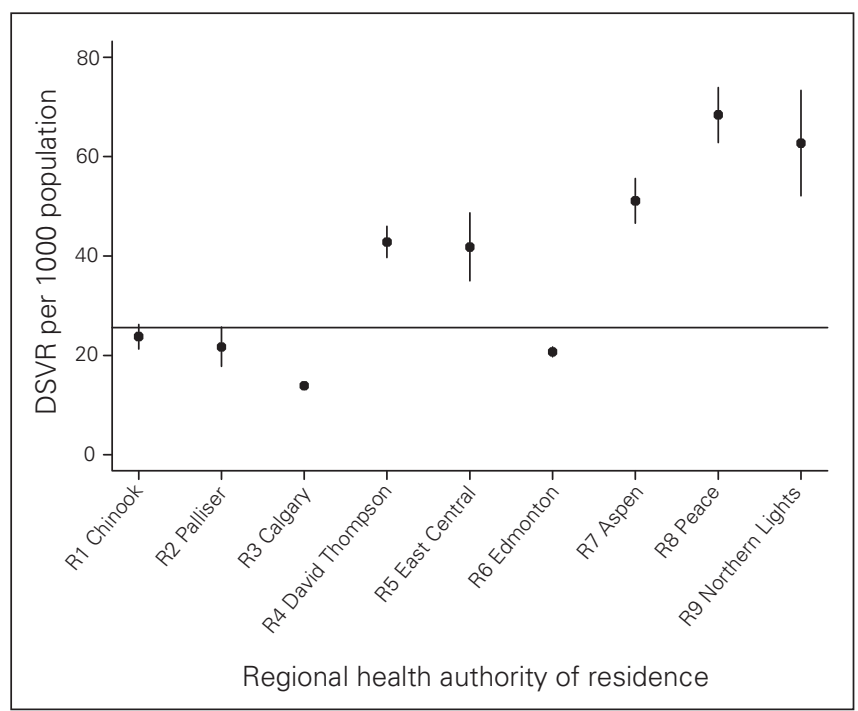

Fig. 5. Age-sex directly standardized visit rates (DSVRs) per 1000 population (age $\geq 55 \mathrm{yr}$ ) and $95 \%$ confidence intervals for fiscal year 2004/05, by regional health authority of residence.

\begin{tabular}{|c|c|c|c|c|c|c|}
\hline \multirow[b]{2}{*}{ Region } & \multicolumn{6}{|c|}{ Fiscal year; DSVR (SD) [95\% CI] } \\
\hline & $1999 / 2000$ & $2000 / 01$ & $2001 / 02$ & $2002 / 03$ & $2003 / 04$ & 2004/05 \\
\hline All Alberta & $\begin{array}{c}25.6(0.4) \\
{[24.8-26.4]}\end{array}$ & $\begin{array}{c}24.4(0.4) \\
{[23.6-25.2]}\end{array}$ & $\begin{array}{c}24.8(0.4) \\
{[24.0-25.6]}\end{array}$ & $\begin{array}{c}21.8(0.4) \\
{[21.2-22.5]}\end{array}$ & $\begin{array}{c}25.0(0.4) \\
{[24.3-25.7]}\end{array}$ & $\begin{array}{c}25.6(0.4) \\
{[24.8-26.3]}\end{array}$ \\
\hline \multicolumn{7}{|c|}{ Regional health authority of residence } \\
\hline R1 Chinook & $\begin{array}{c}27.8(1.7) \\
{[24.4-31.3]}\end{array}$ & $\begin{array}{c}27.5(1.7) \\
{[24.2-30.8]}\end{array}$ & $\begin{array}{c}32.6(3.3) \\
{[26.2-39.0]}\end{array}$ & $\begin{array}{c}22.2(1.2) \\
{[19.8-24.5]}\end{array}$ & $\begin{array}{c}25.0(1.3) \\
{[22.5-27.6]}\end{array}$ & $\begin{array}{c}23.8(1.3) \\
{[21.3-26.2]}\end{array}$ \\
\hline R2 Palliser & $\begin{array}{c}20.6(3.8) \\
{[13.2-27.9]}\end{array}$ & $\begin{array}{c}17.0(2.4) \\
{[12.3-21.6]}\end{array}$ & $\begin{array}{c}13.3(1.2) \\
{[11.0-15.6]}\end{array}$ & $\begin{array}{c}15.2(1.4) \\
{[12.5-18.0]}\end{array}$ & $\begin{array}{c}18.9(1.5) \\
{[16.0-21.8]}\end{array}$ & $\begin{array}{c}21.7(2.0) \\
{[17.8-25.7]}\end{array}$ \\
\hline R3 Calgary & $\begin{array}{c}15.3(0.5) \\
{[14.4-16.2]}\end{array}$ & $\begin{array}{c}13.8(0.5) \\
{[12.9-14.7]}\end{array}$ & $\begin{array}{c}13.8(0.4) \\
{[13.0-14.7]}\end{array}$ & $\begin{array}{c}12.9(0.4) \\
{[12.1-13.7]}\end{array}$ & $\begin{array}{c}13.7(0.4) \\
{[12.8-14.5]}\end{array}$ & $\begin{array}{c}13.9(0.4) \\
{[13.1-14.6]}\end{array}$ \\
\hline R4 David Thompson & $\begin{array}{c}46.6(1.7) \\
{[43.2-49.9]}\end{array}$ & $\begin{array}{c}38.2(1.5) \\
{[35.3-41.2]}\end{array}$ & $\begin{array}{c}40.9(2.0) \\
{[36.9-44.9]}\end{array}$ & $\begin{array}{c}31.5(1.2) \\
{[29.1-33.9]}\end{array}$ & $\begin{array}{c}38.4(1.4) \\
{[35.7-41.2]}\end{array}$ & $\begin{array}{c}42.8(1.6) \\
{[39.7-46.0]}\end{array}$ \\
\hline R5 East Central & $\begin{array}{c}40.3(2.4) \\
{[35.7-45.0]}\end{array}$ & $\begin{array}{c}44.8(2.7) \\
{[39.6-50.0]}\end{array}$ & $\begin{array}{c}49.3(2.9) \\
{[43.7-54.9]}\end{array}$ & $\begin{array}{c}37.5(2.6) \\
{[32.4-42.6]}\end{array}$ & $\begin{array}{c}39.9(2.3) \\
{[35.4-44.4]}\end{array}$ & $\begin{array}{c}41.8(3.5) \\
{[35.0-48.7]}\end{array}$ \\
\hline R6 Edmonton & $\begin{array}{c}19.0(0.6) \\
{[17.9-20.1]}\end{array}$ & $\begin{array}{c}18.6(0.6) \\
{[17.5-19.8]}\end{array}$ & $\begin{array}{c}18.6(0.5) \\
{[17.5-19.6]}\end{array}$ & $\begin{array}{c}18.0(0.5) \\
{[17.1-19.0]}\end{array}$ & $\begin{array}{c}20.8(0.6) \\
{[19.7-21.9]}\end{array}$ & $\begin{array}{c}20.7(0.5) \\
{[19.7-21.7]}\end{array}$ \\
\hline R7 Aspen & $\begin{array}{c}46.7(2.6) \\
{[41.6-51.8]}\end{array}$ & $\begin{array}{c}51.9(3.0) \\
{[46.1-57.8]}\end{array}$ & $\begin{array}{c}47.9(2.6) \\
{[42.9-53.0]}\end{array}$ & $\begin{array}{c}44.9(2.3) \\
{[40.5-49.3]}\end{array}$ & $\begin{array}{c}53.5(2.4) \\
{[48.8-58.2]}\end{array}$ & $\begin{array}{c}51.1(2.3) \\
{[46.6-55.6]}\end{array}$ \\
\hline R8 Peace & $\begin{array}{c}61.9(2.7) \\
{[56.5-67.2]}\end{array}$ & $\begin{array}{c}56.7(2.5) \\
{[51.8-61.5]}\end{array}$ & $\begin{array}{c}60.1(2.7) \\
{[54.8-65.4]}\end{array}$ & $\begin{array}{c}54.4(2.3) \\
{[49.8-59.0]}\end{array}$ & $\begin{array}{c}63.8(2.6) \\
{[58.6-68.9]}\end{array}$ & $\begin{array}{c}68.4(2.8) \\
{[62.8-73.9]}\end{array}$ \\
\hline R9 Northern Lights & $\begin{array}{c}43.4(4.4) \\
{[34.8-52.0]}\end{array}$ & $\begin{array}{c}50.0(6.1) \\
{[38.1-61.9]}\end{array}$ & $\begin{array}{c}45.6(4.8) \\
{[36.2-55.0]}\end{array}$ & $\begin{array}{c}48.5(6.2) \\
{[36.4-60.7]}\end{array}$ & $\begin{array}{c}63.4(5.5) \\
{[52.5-74.3]}\end{array}$ & $\begin{array}{c}62.7(5.4) \\
{[52.1-73.3]}\end{array}$ \\
\hline
\end{tabular}


ences between the regions with the lowest rates and the highest rates could arise from differences in smoking rates, availability of alternative sources of care other than the ED or patterns of medical practice and/or ED usage. Methods of diagnosis and/or distribution of high-risk populations must also be considered; for example, patients with severe or end-stage COPD may relocate to regions where specialized care is available. Moreover, large Aboriginal communities located in a region may cause skewing of data. Further research is required to help explain the geographic variations we have identified.

\section{Limitations}

Our study has several limitations. A number of ways exist in which our data could underestimate the prevalence of COPD exacerbations. First, because many people report to their family physicians or local clinics for treatment, the ED setting would not capture all cases. Second, the lower rates of ED visits for COPD among the young elderly (55-64 yr) may be the result of misclassification of COPD cases as "asthma." ${ }^{20}$ Evidence suggests that patients presenting to the $\mathrm{ED}$ who receive a diagnosis of COPD can be assumed to have the disease, ${ }^{21,22}$ however, misclassification of COPD as asthma or reactive airway disease could further underestimate the prevalence. ${ }^{23}$ Finally, in patients seeking care for reasons other than COPD, COPD is an important comorbidity that we would have missed.

The patterns observed could have arisen from differences in emergency service delivery or preferences for emergency services in some populations and may not represent systematic differences in the illness distribution. The classification of Aboriginal status in these data includes only Aboriginals for whom the First Nations and Inuit Health Branch of Health Canada pay the health care premiums to the province; thus, some people of Aboriginal or Metis status are not included. The ACCS database provides limited information about disease management in the ED, and so our results may not be generalizable to other settings (analogous to the fact that admissions for COPD treatment differ between Canadian and American EDs $\left.{ }^{24}\right) \cdot{ }^{14}$ Finally, few EDs in Alberta have a truly computerized emergency department information system, so some data entered into the ACCS may represent estimates or be missing. Despite these concerns, these data have been shown to be valid and reliable, and we feel the problems we have outlined would not substantively bias our findings.

\section{CONCLUSION}

Chronic obstructive pulmonary disease is a common presenting problem in Alberta EDs. Marked regional, daily and socio-demographic variations exist; however, the reasons for these variations are unclear and merit further study. The most notable findings are an overall increase in the number of COPD presentations during the study period, relatively stable rates of presentation during the study period, and disparities in presentations based on age, sex, cultural or economic status, and region. Understanding COPD presentations should assist policy-makers in addressing specific groups for targeted interventions.

Acknowledgements: The authors greatly appreciate the efforts of Yan Jin at Alberta Health and Wellness in facilitating access to the data and Dan Metes for assisting in data analysis. The authors appreciate the cooperation of the COPD \& Asthma Network of Alberta (CANA, www.canahome.org), especially Eileen Gresl, CANA Manager, in facilitating involvement of these decision-makers.

This work has been made possible by an operating grant from the Canadian Institute of Health Research and funding from the Lung Association, Alberta and North West Territories. Dr. Rosychuk is supported by the Alberta Heritage Foundation for Medical Research as a health scholar. Dr. Rowe is supported by the Government of Canada as a 21st century Canada research chair.

Competing interests: None declared for Drs. Rosychuk, Voaklander, Senthilselvan, Klassen and Marrie. Dr. Rowe has received research funding and speaking fees from AstraZeneca, GlaxoSmithKline and Abbott and consulting fees from AstraZeneca.

Disclaimer: This study was based in part on data provided by Alberta Health and Wellness. The interpretation and conclusions contained herein are those of the researchers and do not necessarily represent the views of the Government of Alberta. Neither the government nor Alberta Health and Wellness express any opinion in relation to this study.

\section{REFERENCES}

1. O'Donnell DE, Aaron S, Bourbeau J, et al. Canadian Thoracic Society recommendations for management of chronic obstructive pulmonary disease - 2007 update. Can Respir J 2007;14 Suppl B:5B-32B.

2. Mannino DM, Homa DM, Akinbami LJ, et al. Chronic obstructive pulmonary disease surveillance - United States, 1971-2000. MMWR Surveill Summ 2002;51:1-16.

3. Global Initiative for Chronic Obstructive Lung Disease. Global strategy for the diagnosis, management, and prevention of chronic obstructive pulmonary disease. 2006. Available: 
www.who.int/respiratory/copd/GOLD_WR_06.pdf (accessed 2010 Sep. 17).

4. Alberta Health and Wellness. Ambulatory care in Alberta using Ambulatory Care Classification System data. Edmonton (AB): Alberta Health and Wellness; 2004.

5. International Classification of Diseases, 9th revision, clinical modification. 3rd ed. Washington (DC): US Department of Health and Human Services; 1989.

6. Canadian Institute for Health Information. The Canadian enhancement of ICD-10. Ottawa (ON): The Institute; 2001.

7. Colman I, Dryden DM, Thompson AH, et al. Utilization of the emergency department after self-inflicted injury. Acad Emerg Med 2004;11:136-42.

8. Kelly KD, Rowe BH, Lissel H, et al. Sport and recreationrelated head injuries treated in the emergency department. Clin 7 Sport Med 2001;11:77-81.

9. Voaklander DC, Kelly KD, Sukrani N, et al. Sledding injuries presenting to the emergency department in a northern city. Acad Emerg Med 2001;8:629-35.

10. Alberta Health and Wellness. Map of health regions prior to April 1, 2009. Available: www.health.alberta.ca/services /health-regions.html (accessed 2010 Feb. 9).

11. Indian and Northern Affairs Canada. Terminology. Available: www.ainc-inac.gc.ca/ap/tln-eng.asp (accessed 2009 Mar. 2).

12. Carriere KC, Roos LL. Comparing standardized rates of events. Am J Epidemiol 1994;140:472-82.

13. S-Plus Version 8.0.4 for Linux 2.4.2. Palo Alto (CA): TIBCO Software Inc.; 2007.

14. Tsai C-L, Sobrino JA, Camargo CA Jr. National study of emergency department visits for acute exacerbation of chronic obstructive pulmonary disease, 1993-2005. Acad Emerg Med 2008;15:1275-83.

15. Mannino DM, Braman S. The epidemiology and economics of chronic obstructive pulmonary disease. Proc Am Thorac Soc 2007;4:502-6.

16. Rowe BH, Bond K, Ospina M, et al. Frequency, determinants, and impact of overcrowding in emergency departments in Canada: a national survey of emergency department directors. Ottawa (ON): Canadian Agency for Drugs and Technologies in Health; 2006.

17. Scott S, Walker P, Calverley PMA. COPD exacerbations. 4: prevention. Thorax 2006;61:440-7.

18. Sin DD, Wells H, Svenson LW, et al. Asthma and COPD among Aboriginals in Alberta, Canada. Chest 2002;121:1841-6.

19. Chapman KR. Chronic obstructive pulmonary disease: Are women more susceptible than men? Clin Chest Med 2004;25: $331-41$

20. Cydulka RK, Rowe BH, Clark S, et al. Gender differences in emergency department patients with COPD exacerbations. Acad Emerg Med 2005;12:1173-9.

21. Radeos MS, Cydulka RK, Rowe BH, et al. Validation of selfreported chronic obstructive pulmonary disease among patients in the ED. Am J Emerg Med 2009;27:191-6.

22. Stieb DM, Beveridge RC, Rowe BH, et al. Assessing diagnostic classification in an emergency department: implications for daily time series studies of air pollution. Am 7 Epidemiol 1998;148:666-70.

23. Aaron SD, Vandemheen KL, Boulet LP, et al. Overdiagnosis of asthma in obese and nonobese adults. CMAJ 2008;179: $1121-31$

24. Rowe BH, Cydulka R, Tsai CL, et al. Comparison of Canadian versus United States emergency department visits for chronic obstructive pulmonary disease exacerbation. Can Respir J 2008;15:295-301.

Correspondence to: Dr. Rhonda Rosychuk, Department of Pediatrics, University of Alberta, 9423 Aberhart Centre, 11402 University Ave. NW, Edmonton AB T6G 2J3; rhonda.rosychuk@ualberta.ca 